\title{
Enhancing Learning Interaction through Inter- Forum Group Discussion in Online Learning: A Case Study on Online Teaching of Research in English Language Teaching Course
}

\author{
Sunu Dwi Antoro \\ Sudilah \\ Universitas Terbuka, Jakarta Indonesia
}

\begin{abstract}
This research aimed to develop a model of Inter-Group Discussion Forum (IGDF) application as media to increase students' interaction and participation in the discussion forum during the online learning. Data were collected through the process of the implementation of discussion forum using IGDF application during the online learning of Research in English Language Teaching (ELT) courses during the teaching period of 2014.2. Data of the students participation were collected through online observation, and data about the students' perception of the IGDF model were collected by providing an online close and open ended questionnaires and analyzed by calculating the percentage. The results of this study indicated that the application of IGDF is applicable in online learning. The amount of participation and the quality of the interaction from the discussion through IGDF has not shown significant improvement. The main obstacle came from the technical problems associated with passwords and the ability to follow the discussion in a discussion forum between groups. However, the variety types of posting has increased. Each group is able to post presentations, questions, responses, and commands. Students' perceptions toward the IGDF proved significant where there was $88.46 \%$ of them stated that the discussion forum with IGDF is very good discussion among the group and it can increase interaction among students in the online learning.
\end{abstract}

Keywords: Discussion forums, group discussion, online interaction, online teaching and learning

\section{INTRODUCTION}

Online learning requires active participation of the students in order to gain the learning objective. It is asynchronous e-learning using media facilities such as e-mail, discussion forums, chatting to establish Enhancing Learning Interaction through Inter-Forum Group Discussion in 64 Online Learning: A Case Study on Online Teaching of Research in English Language Teaching Course 
interaction between learners with learning materials and learners with tutors, and learner with learner, even when students are not online at the same time. (Hrastinski, 2008). The online learning facilities can contribute to the understanding module whenever the learning scenarios provide self-learning facilities through initiation and interaction. The meaning of e-learning according to Clark, Ruth Colvin (2002: 13): We defined elearning as instruction delivered on computer by way of CD-Rom, Internet, or internet with the following features:

- Includes content relevant to the leaning objectives

- Uses instructional methods such as examples and practice to help learning

- Uses media elements such as words and pictures to deliver the content and methods

- Builds new knowledge and skills linked to individual learning goals or to improved organized performance.

Thus, e-learning includes internet-based learning materials, methods, media and learning activities. The principle of the teaching and learning process remains the same as in the face to face learning. The difference is tutors' creativity in making the student learning process and also the media of interaction. One form of online learning activities that allows the interaction of learning is utilizing the discussion forum. Discussions are commonly used in online teaching and have been shown to foster student learning and collaboration. Peretz (2014).

Online discussion is asynchronous which means that all students can log in online learning and participate in discussions at a time that suits them (Bender,2003: xvi). Discussion forums conducted by the tutors in general is still in the form of a model where the tutor as a moderator. The problems that arise with this model is generally feedback still on the individual. Tutor gives problem to the students and then asked them to respond. Tutor gives feedback to the students' response or commands. (Gadne,at.al.2005). Discussion forums should be designed to create the activities and interactions in online learning. Therefore, there should be a model of a discussion forum that can accommodate the role of students more than just give a response. To make the students have more roles in the discussion forum there should be and Inter Group Discussion Forum application.

\section{METHODOLOGY}

This research is a development research to create a model of online Inter Group Discussion Forum application to be applied in the online learning of Research in ELT course period 2014.1 and 2014.2. This application is designed to increase student interaction and participation. Data were

Enhancing Learning Interaction through Inter-Forum Group Discussion in 65 Online Learning: A Case Study on Online Teaching of Research in English Language Teaching Course 
collected through a process of the trial of IGDF model implementation by applying an action research technique during the period of online learning 2014.1. Data were collected through the process of increasing interaction during the application of IGDF, observation and reflection implementation results of the implementation in each cycle. Data evaluation of the model IGDF is collected by providing an online questionnaire to the students' learning of Research in ELT courses.

IGDF is designed to provide an opportunity not only to interact and provide feedback, but it can facilitate each group to present the given topic from tutor. Therefore, each group can display different material and share opinions and discuss the content of the module with another group. During the process of discussion, every member was asked to give command or response to the other group. The scenario of IGDF was planned to increase the students' participation and it will make the student more active in the online learning process. Based on this idea the research questions were 1) How to design Inter Group Discussion Forum application (IGDF)?; 2) How do students' perceptions of the model IGDF in online learning?; and 3) Does IGDF increase the participation and quality of interaction online learning?

\section{Design of IGDF}

The Inter-Group Discussion Forum (IGDF) online was developed to increase participation and student's active learning in the course of Research in English Language Teaching (Research in ELT). Here is the scenario model of inter-group discussions in online learning.

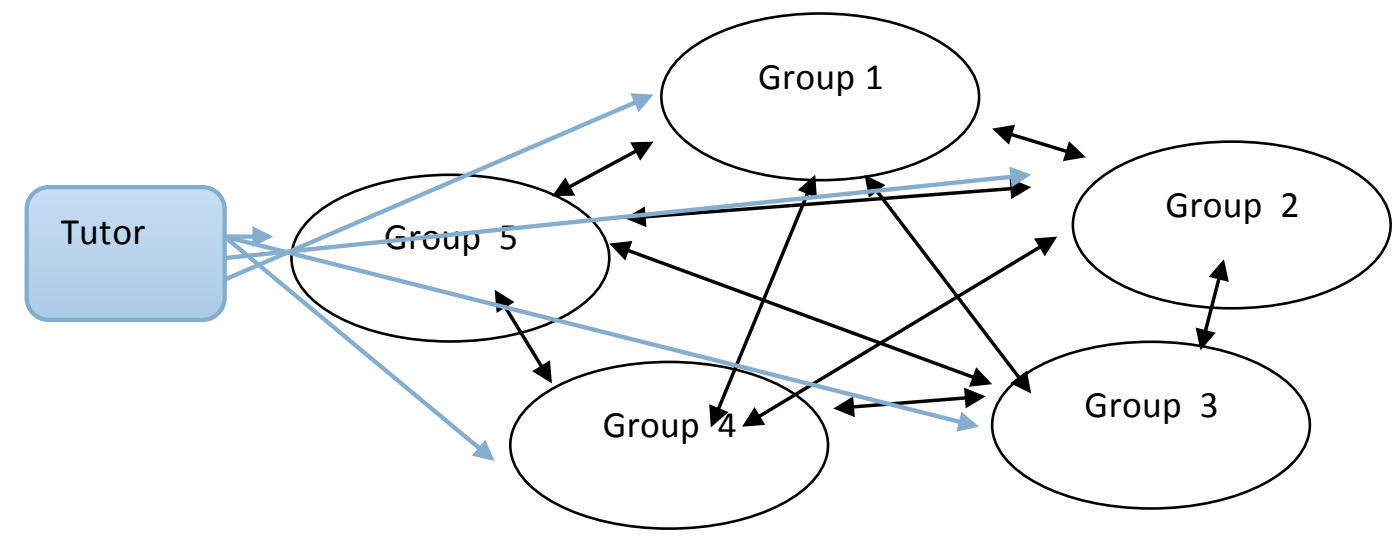

The procedure of IGDF development starts by grouping the students into $5-7$ groups. Each group was required to make a presentation based on materials that are assigned by the tutors in their learning group, submit the question of discussion in accordance with the material presented, 
respond to questions, ask questions, and give opinions related to the material. Tutor give feedback for each group.

\section{Students/research participants}

This research was conducted in English Education Study Program at the Faculty of Education Universitas Terbuka, Indonesia. The subjects of this study were the students who took the Research in English Language Teaching Course and participated the online learning of this course at the 2014.2 period. Data collection techniques used in this study was observations participation during the applying the model inter-group discussions, and close and open ended questioner. The enclosed questionnaire was means to gain information from the respondents (students participating in online) concerning their perception and responses to the discussion forum application and practices of IGDF. The open questionnaire was given to the students to confirm the results of the data collection through the enclosed questionnaire. The research was conducted in the first semester registration period 2014.1 as test models of IGDF models. The implementation of IGDF was done in the second semester (2014.2 registration periods) during the learning of the subject PBIS4401/ Research in ELT.

Here is a table of students' profile of Research in ELT courses online learnings during the 2014.2 period.

Table 1. Students Profile on the Online Learning of Research in ELT course:

\begin{tabular}{|c|l|c|}
\hline NO. & \multicolumn{1}{|c|}{ Students Profile } & $\begin{array}{c}\text { Number of Students } \\
\text { Accessed }\end{array}$ \\
\hline 1 & $\begin{array}{l}\text { Students were enrolled in online learning of } \\
\text { Research in ELT course during the 2014.2 } \\
\text { period }\end{array}$ & 106 \\
\hline 2 & Students who access the learning & 73 \\
\hline 3 & Students who were active in the discussion & 25 \\
\hline 4 & Students who completed questionnaires & 42 \\
\hline
\end{tabular}

\section{Research Procedure}

This study is a qualitative research to find effective models online group discussions in increasing the students' participation in taking the subjects PBIS4401 / Research in ELT. Research procedures comprises of a) Prepare the Proposal; b) Develop of close and open ended questionnaires; c) Develop online Inter- Forum Group Discussion (IGDF ); d) Conduct trials IGDF model of an online discussion forum; e) Perform reflection and improvement models of Forum Inter-group discussion forum based on the 
first trial results; f) Apply the model of the Inter-Group Discussion Forum; g) Collect data though observations; h) Collect data through closed and open questionnaires; i) Data processing; $j$ ) Interpretation of the data processing; k) Writing Draft Report

\section{REVIEW OF LITERATURE}

At this time we have been at the era of advanced communication technologies. Communication technology has grown through the internet network on computer media. The Internet is a network of information over the phone connected to the computer. Internet is a net which is also known as cyberspace, information superhighway, online communications, electronic library and digital revolution. Teeler \& Gray (2000). Basically, the Internet is an information network that is connected to the telephone network is connected to the computer. There are various ways of transportation information using a wide variety of application programs such as e-mail and the web. In the mode of learning strategy learning based on the use of internet often known as e-learning.

\section{Online learning components}

Online learning is designed to support the learning process in the distance learning system. It is one of the learning support packaged in a built-up online learning application that allows tutors and students can interact in asynchronous system. The activities in online learning comprises of at least 3 types of activities, namely: reading the initiation, taking part in discussion forum, and doing either tasks or assignments. Initiation is learning material uploaded by tutors to initiate the students in order to start the learning process. Initiation can be made in several types: text pages, web pages, links to files or web. The form of initiation can also perform activities such as reading a text that serves as a supplement (material enrichment) to students. Discussion forum provides the students to participate the asynchronous interaction by reading the initiation from the teacher and giving the response or command depends on the learning problems given by tutor. Tasks and assignments are given to the students to measure their learning achievements.

\section{Design and Development of Online Learning}

Designing online learning includes learning system (instructional delivery) and the media that support the online learning. Like face to face learning, online learning also begins with a preparation by tutors, and media interaction using the internet and the media as supporter moodle learning. Media interaction is used by tutors are online learning media. The development of online learning covers the preparation, implementation and evaluation. Preparation of online learning was

Enhancing Learning Interaction through Inter-Forum Group Discussion in

Online Learning: A Case Study on Online Teaching of Research in English

Language Teaching Course 
started from the manufacturing part of the online learning itself which includes the manufacture of design activity, initiation, interaction, tasks and exercises, as well as learning materials and discussions scenarios for the board. In this preparation also includes preparing Course Management Systems (CMSs) Simonson. (2012. P: 126).

In distance learning system, online learning become a medium of learning process that is needed as virtual classrooms as well as things done in the face-to-face learning. The implementation selected online learning is an online learning structure designed as a learning class concept that allows the interaction and learning process. As described by McBrien. J.L; Jones. P, \& Cheng.R. (2009: p.3) stated that the theory of transactional distance learning system at least consist of three elements: dialogue, structure, and the autonomy of learners; all of which are interrelated and interconnected to build interaction of learners with tutors, learners with learners, learners with the learning material. Oren A, Mioduser D. and Nachmias.R. (2002) explains that the communication characteristics of a unique internet-based media have contributed to the development of a wide variety of group work models, ranging from discussion groups up to the understanding of the learning society.

\section{Delivery of online learning}

Online learning in a distance learning system is designed as learning support services for the students to facilitate additional services to assist them in understanding and assessing teaching materials subject being studied. Students are required to participate in online learning. Reward given to students who follow the learning actively and doing all the tasks given by tutor then they will get the value of a contribution of $30 \%$ of the final examination of the courses they take. In online learning, student learning activities are under the guidance by tutor as a facilitator of learning. Learning activities are in the form of discussion of learning materials that are considered difficult and very important. For more details, the learning materials covered in the learning activities involve the discussion about the competence or important concepts in the module; the problems found in the module; issues related to the student in learning module, and the problems associated with the application of science in everyday life.

In an online learning, students are required to participate actively in online learning process. In order to keep up with a good learning, students should read the module, read the initiation, do exercises, be active in discussion forums, and finish the tasks and assignments. Thus, all kinds of difficulties in understanding the learning material in the module can be discussed with the tutor and with other students. To take part in

Enhancing Learning Interaction through Inter-Forum Group Discussion in 69

Online Learning: A Case Study on Online Teaching of Research in English Language Teaching Course 
discussions forum, students can view the contents of a topic of discussion, then they need to access the title of the discussion, after which the screen will appear to give feedback. Provide feedback to students on the topic of their discussion can click the "Response", as it would appear to form them to write their responses, and then they have to send their response to the "Post to forum" to submit feedback.

In addition to provide feedback on the discussion forum, the students are also possible to create a new discussion topic. It will allow them to talk with the tutor about the course content which is considered difficult. To create a new topic in a forum discussion, the students simply click on the "Add" button topic of discussion recently, after the form will appear where they can write the topics they want to discuss with the tutor and other students, after they finished writing the title and subject to discussion, then they can click on a post to the forum to post a new topic. Another part of the online learning to be followed by the students is doing the tasks and assignments. There are three assignments that must be answered by the students. Assignments are given in the third week of online learning, fifth and seventh week. Similar to the above two types of activities, to see that the task has been given by the teacher, the students only need to click on the title of the task, after the task is clicked it will display the full contents of the tasks that have been prepared by the teacher. The students just go ahead and read the material carefully and then answer the task.

\section{Using Online Learning as Virtual Classroom Instruction}

Online learning as a place of learning process that allows the tutor to design learning process virtually includes delivery of materials, exercises, discussion, question and answer, and giving tasks and evaluation. In order for the implementation of learning process run well tutors are required to conduct preparatory phase, then the implementation and ends with evaluation. To start the online learning, tutor can start by the preparations. According to Teeler \& Gray (2000: 54) it can be carried out the following steps:

\section{Step one: Prepare good Online Learning Plan}

To prepare online learning, tutor can begin by checking the possibility of learning the internet or not. First look at the availability of computers in the teaching, the room and the students' ability to operate a computer. Equipment that need to be considered include whether there is a CD-ROM drive, speaker, headphone, microphone, projector, scanner. The next steps set the rooms that include the position of teachers and students. Student position can be set the same as regular classes, or U-shaped or groups. This setting is adjusted to the interests of the learning process. 


\section{Step two: Create good activity in the Internet-based learning}

Before a tutor writes the design of learning activities of internet-based English learning, he/she must specify learning objectives beforehand. Guidelines are a reference in determining the learning objectives of English with the internet-based activities are as follows: What do you expect to be achieved by students through the activity of internet-based learning English? Why this activity is determined using the internet other than the media? How long learning activities that can be completed, part of the study, some learning or throughout the year? With whom the student will communicate, communicate in one classroom, with another class, with other schools in the city, with other school in different cities, with other schools in different countries? Are you planning use this activity with more than one class or one level?

One way to start is by studying the structure the task referenced handbook staple in learning. Select learning activities that will not run smoothly in the classroom, which does not challenge students to get involved or interested in learning activities, or for any reason that everything is not expected to be effective. Analyze the activities that will be conducted this study will encourage you to use the internet to carry out the learning activities that are expected to be ineffective in doing the activity using the other media.

After determining the specific application that will be used in the learning activity, the next step is to determine the place used, compile mailing lists or websites. To decide the place use certain criteria to evaluate and determine the place. The actual determination of the place depends on the condition of the school and the application that will be used. After determining the place, then perform design activities in accordance with the purpose and place specified. In addition, forms of communication to be performed must be determined in order to support the achievement of objectives. Internet-based communication with communication asynchronous communication can be done by e-mail between individuals, in a mailing list, using a public space such as conferences, newsgroups, bulletin board. (Weller, 2002: 83). Asynchronous communication is communication model most widely applied in learning using internet technology media or often known as online courses.

\section{Discussion Forum}

Discussion forum in an online learning is a learning application that can be used to communicate in asynchronous way by posting ideas / opinions / comments / questions online. Raleigh (2000) says: 
"... online discussions are the asynchronous posting of electronic messages by members of a class in a continued conversation on topics designated by the instructor.

Online discussion is very useful to facilitate online learning". Actual application of online discussion can be divided into two. The first details the conceptual basis for the online discussion, and both the practical application of the online discussions that lead to conceptual learning. Raleigh (2000). Loncke. F.T; Dudding.C.C; Kim.J (2009) online discussion is a discussion forum for learning through online communication where tutors and students can conduct a discussion about the subject matter.

Discussion forums can be performed asynchronously, which means that each participant can post the material in different form. Discussion forums actually the same as face-to-face group discussions, only in online discussion forums are nonverbal and visual exist between participants. Online class discussions give the instructor the opportunity to 'see' what learners are thinking and to 'see' which learning materials are considered difficult by the students. With that information, the instructor can offer help, and building remediation. (Gunawardena and LaPointe.2003: 185). Scenario discussion group by dividing the students into small groups to respond to cases that help them to apply theories and concepts presented in class or in reading text. According to Raleigh (2000) the group discussions can be applied in the learning activities such as brainstorming activity. This activity is an activity before starting discussions, here students can use online discussion format to brainstorm ideas about a topic.

\section{FINDINGS and DISCUSSION}

\section{Research Question 1. How to design the online IGDF model? 1) Developing online IGDF}

The online IGDF was developed to provide online discussion forums between the groups so that the students have more than one role. Not only do they post the response from the teacher but they can post presentation and question either. IGDF application was designed to facilitate the discussion group participation like in the face to face discussion. As it was noted by Bender (2003: 120) that it might be helpful to divide the class into groups, and they have a discussion group leader. Effective teaching in higher education requires students to spend a lot of time to learn through active involvement as group discussions with their peers. (Weimer, 2002) in (Peretz) 2014). Although learning the initiation, module, and answering the assignments, and quiz are a typical component of online learning, creating more interactive learning can occur in a discussion forum. 
The discussion board provides facilities for a diverse range of uses in online classroom situations. By applying online IGDF there will be various communications between the students. It provides the interaction between students in their own group, between students with other members of other group, and between students and tutor, and students with the discussion initiation or dialogue on a topic / subject matter being considered. Such discussion can be asynchronous or synchronous; a forum for interaction and networking among learners / users; a repository of learning materials and artifacts; serve as learning histories to which the learners can refer in the future because of the permanent nature of the record of contributions. (Mishra \& Juwah, 2006: 162). The discussion forum is able to provide board for students and tutors to express questions, opinions, suggestions, objections and other comments related to learning materials in online learning. Based on the above concept of online forum discussion, the development of inter-group discussion refers to the function and role of students as in the face to face inter-group discussions. IGDF was named "Diskusi Kelompok Mata Kuliah Researh in ELT" (Discussion group of Research in ELT Course) as seen in fugure 1.

Figure 1: Application's name of online IGDF in the learning of the Research in ELT course is "Diskusi Kelompok Mata Kuliah Research in ELT"

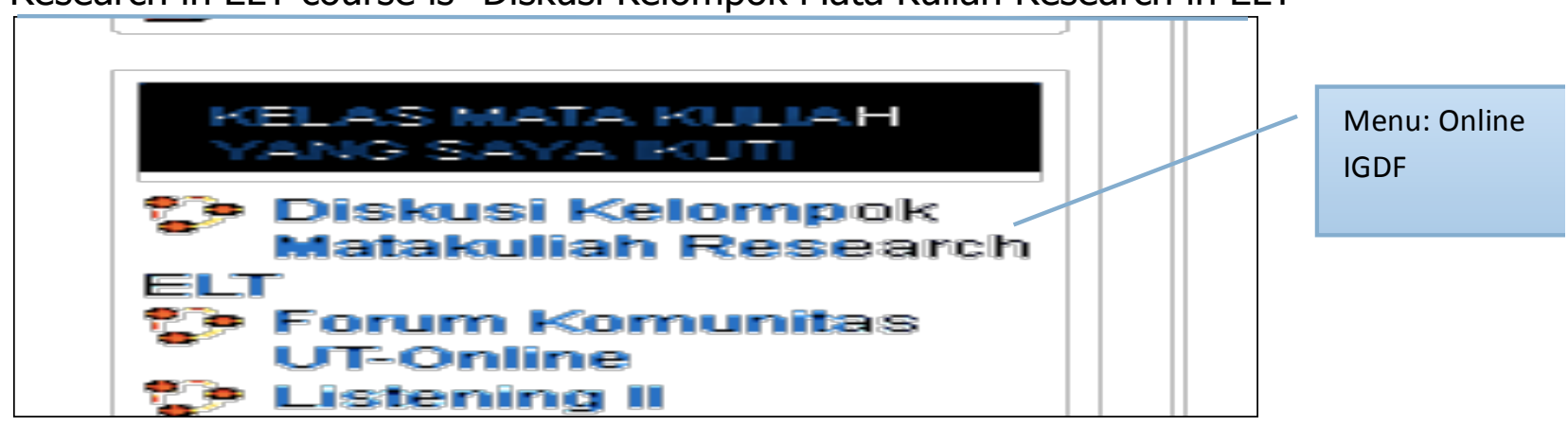

The board of online IGDF application was developed the same application with the online learning courses. However, the application of online IGDF only has one menu that is a forum for group discussion. Fill menus in the group discussion were menu groups called group 1, group 2, group 3, group 4 and group 5 in $n$ each group. 
Figure 2: Page application IGDF

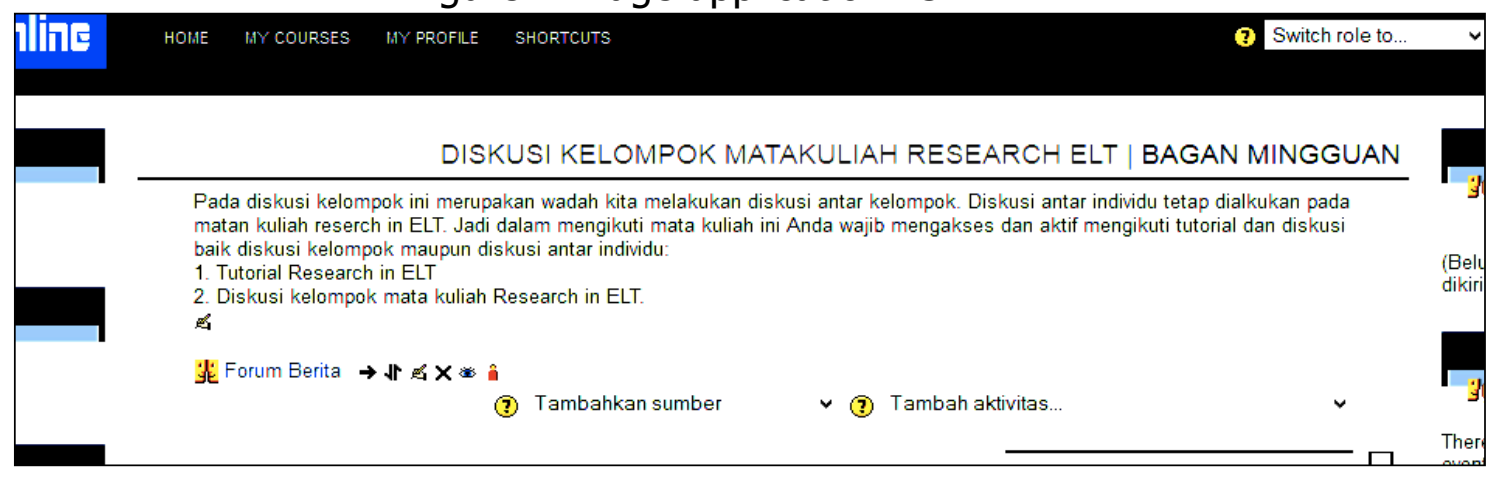

Figure 2 illustrates the same board like in the learning course of Research in ELT. The board is named Discussion groups of subjects Research in ELT. In figure 3 is one example of a weekly chart that contains menus group of 1 to 5 to give each students the opportunity to access their respective groups and access to other groups to join the discussion with other group.

Figure 3. Fill Menu groups

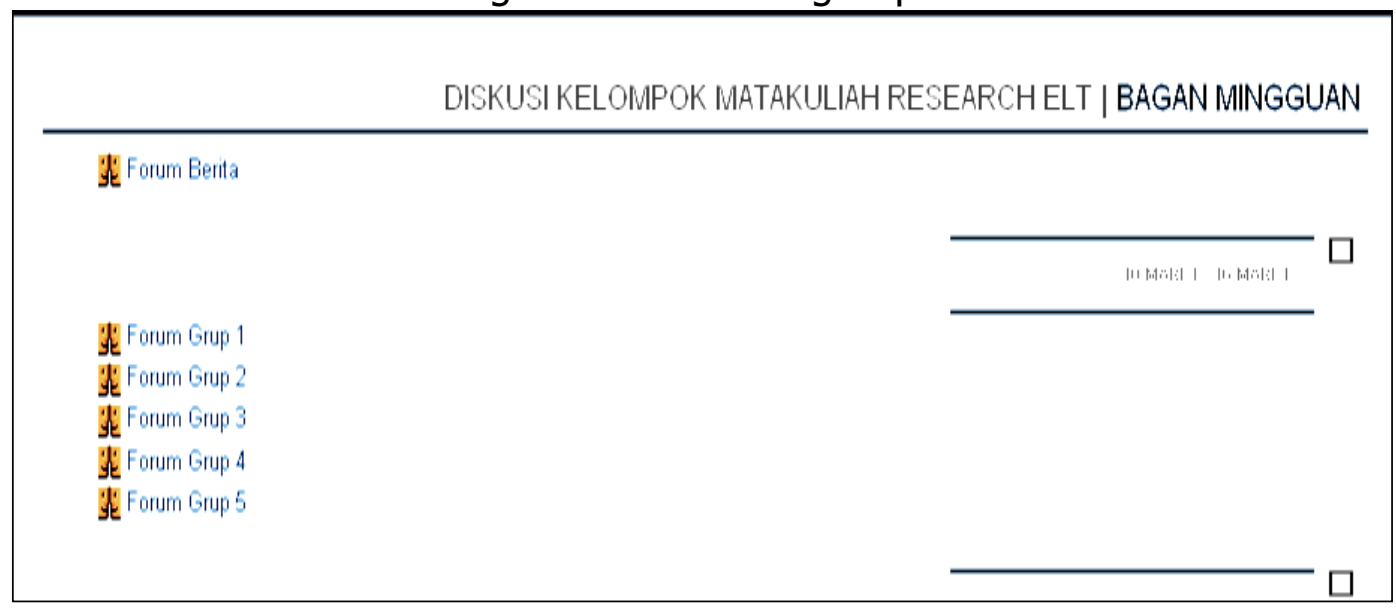

\section{2) Try Out IGDF Application}

To know whether the IGDF application was running well and applicable or not, it needed to be applied before it was used. The students who enrolled the online learning of Research in ELT course during the 2014.1 learning period were grouped into 5 groups, and then named group 1 - group 5 . The trial of the IGDF application for the discussion in the group and between groups was made during the learning on March 10 at the learning week 2 . The trial focused on the utilization of group discussion system. It was done by asking the students of online learning on the Research in ELT course to access the IGDF and then they accessed their own group. The students are allowed to practice accessing the group

Enhancing Learning Interaction through Inter-Forum Group Discussion in 74

Online Learning: A Case Study on Online Teaching of Research in English Language Teaching Course 
discussion application by accessing other groups. The data access discussions linear models that exist in the learning pages of research in ELT courses are as follows:

Table 2: Students who access the discussion

\begin{tabular}{|c|c|l|}
\hline Discussion week & $\begin{array}{c}\text { Amount of } \\
\text { access }\end{array}$ & \multicolumn{1}{|c|}{ Posting Content } \\
\hline 1 & 25 & $\begin{array}{l}\text { Presentations, questions and complaints } \\
\text { about not being able to access to } \\
\text { discussion group }\end{array}$ \\
\hline 3 & 18 & Answering questions \\
\hline 6 & 5 & Answering questions \\
\hline
\end{tabular}

Each group was given task to discuss in the group and then displays the group's work as their presentation and the uploaded it in their own group. The presentation of each group will be read by other members of the other group. Trial process of inter- group discussions in the IGDF proved that the students were more active because they had to present their material in their group, and they also accessed other group to read other group's material. After they read they were asked to give comment or asked questions. The learning materials discussed in the inter-group discussion using IGDF application was much broader in scope, because each group should present the results of the group discussions within their tasks assigned by tutor. It covered wider learning material to discuss because each group had to present different materials with other groups. The result of the trial of IGDF during the online learning period 2014.1 prove that the application was running well and the students who enrolled the FGDF were able to post the material and also asked questions. Therefore the IGDF was ready to be applied.

\section{Question 2: Is online IGDF models can improve the quality of participation and interaction of students during the online learning?}

To examine the increase students' participation and the quality of interaction in the inter-group discussions forum through IGDF was done by implementing IGDF the online learning of Research in ELT course during the learning period 2014.2. The IGDF implementation is done in 5 weeks.

\section{1) Implementation of IGDF : First Week Online Learning dated on September 1 to 7 second semester 2014.2}

The implementation of online IGDF was carried out during the online learning of Research in ELT course in the period of 2014.2. To prepare the activities the class divides the students who enrolled the online learning of

Enhancing Learning Interaction through Inter-Forum Group Discussion in 75 Online Learning: A Case Study on Online Teaching of Research in English Language Teaching Course 
Research in ELT course into 5 groups and then have discussion leaders through the semesters so everyone has a turn. Group formation procedure was done by choosing the students randomly from a number of students who have been enrolled the online learning of Research in ELT course. The formation of this group was done in the learning week 2 . The results of the division of the group were announced on the online learning board of Research in ELT course on the 1st to 7th of September. In the learning on the forum page news displayed the names of students in each group and the students were asked to try to access the IGDF online applications. Then ask each group to try the application of discussion between groups. To initiate discussion among the group, tutor invited students to begin accessing the "Discussion Group Research in ELT course" Student were asked to response the implementation of this group discussions, and the result of the implementation as seen Table 3.

Table 3: The activities of students in group discussions in the first week:

\begin{tabular}{|c|c|l|}
\hline $\begin{array}{c}\text { Name of } \\
\text { Group }\end{array}$ & $\begin{array}{l}\text { Number of the } \\
\text { students accessed }\end{array}$ & \multicolumn{1}{|c|}{ Posting Content } \\
\hline Group 1 & 5 & $\begin{array}{l}\text { Asking for help to be a member of the } \\
\text { group, demo of the implementation of } \\
\text { group discussions }\end{array}$ \\
\hline Group 2 & 3 & $\begin{array}{l}\text { Asking for help to be a member of the group, } \\
\text { demo of the implementation of group } \\
\text { discussions }\end{array}$ \\
\hline Group 3 & 1 & $\begin{array}{l}\text { Presentation and Taken by two students } \\
\text { from other groups }\end{array}$ \\
\hline Group 4 & 2 & $\begin{array}{l}\text { presentation of questionnaires and } \\
\text { observation post about presentation }\end{array}$ \\
\hline Group 5 & 1 & Presentation of: production task \\
\hline
\end{tabular}

In the first week shows that the students had already known which group she/he belongs to. Each group had a discussion activity as it was seen from the posting content. Commands to the posting of presentations have been initiated by group 2, 3, 4, and 5 . The students from these groups had tried to respond to the presentation of other groups. For example, the presentation of the group 2 which contains the questionnaire has been addressed by two students from other groups. If seen from the number of members it was still very limited access. This proves that the IGDF online application system has been functioning well. It has been able to provide the students to study group and study between groups. There were 12 students who had accessed the group, and each group had its member. 


\section{2) Implementation of IGDF dated on September 8 to September 15, 2014}

To start the implementation for the second week, tutor first wrote the announcement tell the students that they had to accesses the IGDF. Tutor wrote: "Another way to join a discussion group, please click" Discussion Subjects Research in ELT "under the words' Class courses I follow". The position is on the left side column. Please try and do the task." Students asked to access to read the announcement on the learning Research in ELT and then conduct discussions between groups. An increasing number of students in the implementation of this second access declined both from the number of students as well as of the number of the access group. Group 4 were empty participants of the students, in the first stage there were 12 people, in this second meeting there were only 6 people. Posts that there is a post presentation only, no other groups respond.

\section{3) Implementation of IGDF dated September $\mathbf{1 5}$ to September $\mathbf{2 1}$}

Under the conditions of the implementation of phase II on September 8 to September 15, the actions taken are as follows:

a. Improve the action in the implantation in the first week, students who did not understand the implementation of group discussion was asked to read the announcement on the online learning of Research in ELT course.

b. The command is given: "Please click on the" Focus Group Research in ELT Course "in the left column. Then click within their respective group. If you want to ask a question on another group please click the group and gave questions or comments to the group presentation. The task of discussion between groups at week 3 is as follows.

In the group discussions during the first week did not work as expected. Not all groups show their presentation. Therefore, in the third week application of IGDF each group was expected to upload the presentations within their group assignment. The students were asked to upload the presentation by clicking on the box containing the words "Add a new discussion topic". At the bottom of the column intended for other groups to ask questions, comments or clarifications on group presentations. For those who had not joined to the group was asked to choose their own group in the group they like. The result is the number of students who access there are 7 people, while the group who do not access still remains one that is group 4 . The activities are posting answers to questions given to each group. 


\section{4) Implementation to IV dated September 29 to October 5}

The discussion between groups still did not run well. Tutor again asked each member of the group to click the "Discussion Subjects Research in ELT" under menu of "The Online learning that I take" in the left column. As the previous discussion, each group required to upload exposure duties. Another group responded or gave comment, and ask questions. The number of students began to decline access to 4 people.

\section{5) Implementation to $V$ dated October 6 to October 12}

In the implementation of inter-group discussion at this stage $V$ online learning tutor gives a task that must be answered by each member in the group. Each group was also required to comment on the answers of other groups. The number of students who access even stayed 3 people and only two groups that appear. One of the students revealed: "But I still have trouble to go in members of the group, and sometimes as many tasks, I love confused share time with their daily work tasks, not to mention the need to study carefully the contents of the module."

\section{Question 3: How was students' perception of the model inter- group discussion forum in online learning?}

Once a student is involved in the implementation of discussion forums between student groups certainly have the impression to IGDF associated with - aspects include: a) students to IGDF, b) activity in IGDF, c) interaction in IGDF, d) participation in the group:, e) communication in IGDF, f) IGDF material, g) presentation in IGDF, h) increased participation in IGDF, and i) the quality of interaction in IGDF.

The results of student responses to the application in the learning IGDF Research in ELT subjects showed a significant response to the presence of IGDF applications. From the aspect of improving the interaction of respondents who strongly agree that there are $42.31 \%$ and $46.15 \%$ agree. But they still think that this application still need to socialize with good, proven or strongly agree that there are 53.85 and agree there are 42,31 . This is necessary because in the absence of prior socialization students will get caught up in trouble, especially from a technical aspect. So this will reduce the quality of the content of the interaction in the discussion groups and between groups. As been said by one of the respondents "Discussion between groups is a great way to attract the interest of students in an active role following the discussion or understanding of the material but needed more socialization of discussion among this group. Thank you "So socialization is done in one week before the learning is still not enough. 


\section{a) Students' perceptions of the activity in IGDF}

Students who stated that the activity through discussion among these groups was very nice were $61.54 \%$. This means that the students are keen to play an active role in the discussion.

\section{b) Interactions in Group Discussion}

Students' involvement in the inter-group discussion forums indicated that each member had not been actively involved in discussions between members. There are only $50 \%$ said that the presentation was not the result of the communication among the members of the group. It was only the work of individual and she/he uploaded it if the group as a result of group work.

\section{c) Participation in Group Discussion}

The involvement of students in participating in the group was still quite low, there were $67.70 \%$ students agree that most students did not do anything in the group. This means that the $67 \%$ majority of the discussion participants had not participated in group discussions. However, when compared with the activity in the discussion only $38.46 \%$ were active. So it can be said that the students were still active. The response of students who were not actively reflected in the following statement: "To be honest, from the beginning, this discussion forum confuses me. Therefore, I do not know what I should do, it seems that the way of online learning of this course different with other courses". Based on this answer most of the students do not understand how to do discussion between groups.

\section{d) Communication in Group Discussion}

Developing online communication is very popular both in terms of social networks as well as in the learning network. One way of online communication is done through the blackboard. At the forum discussion among these groups turns out $61.53 \%$ of students do not feel the ease in communicating or interacting with members or with other groups.

\section{e) Learning Material for Group Discussion}

There were $57,69 \%$ students said that the learning material in the discussion forum was easy. But there was only $57.7 \%$ students agreed that they were easy to response the discussion material. Thus it could be said that the discussion of learning material was easy to understand but it was difficult to answer.

\section{f) Presentation in Group Discussion}

Cooperation among the member of each group or the inner group discussion had not run well. Students who responded that the group uploaded presentations based on the discussion group only $26.92 \%$. While $65.38 \%$ students said that the presentation of the group uploaded in the IGDF did not come from the discussion group. This means that the process of group discussion was not running well.

\section{g) Increased Participation in group discussions}


The increase of students who participated in the IGDF did not show a positive response, there was $69.23 \%$ students strongly agreed that the IGDF can increase the number of the students.

\section{h) The quality of interaction in group discussions}

There are $76.93 \%$ of the students who expressed strongly agree and agree that the quality of interaction in discussion forums between groups were able to increase the understanding of the learning material. It means that basically the student has judged that the interaction in group discussions can improve the understanding of the material module.

\section{CONCLUSION}

Development of Inter-Group Discussion Forum (IGDF) was designed based on the computer network to make it reflective, asynchronous, structured and multidirections. To develop a prototype model of IGDF application consists of the steps: study scenario existing discussion forums, create scenarios IGDF which is intended to be used for a class of groups 1 , making the same scenario for groups of 2, 3, 4, and 5 . Then, creat a class member and subsequently announced the division of the group, at the time it was registered as a learning students there were 38 students, so the tutor made 5 groups each consisting of between $6-7$ students. In an effort to avoid buildup in one group then announced to the student tutors that each joined the group to tell the tutor.

The amount of participation from the IGDF do not show a significant improvement, as evidenced in the first week there were 12 students, week 2 there were 6 students, there were 7 students in week 3, week 4 there were 4 students, there are 4 to 5 students, and since week 6 there were only 3 students. This was caused by several aspects include: They were unable to access, still confused, and the cooperation had not occurred in each group, the group discussed the mechanism is unclear. On the other hand students who are able to access a positive comment to IGDF nice expressed by adding inputs including socialization, ease of access, need explanation of scenario with exercise. Thus the increase in participation has not appeared still needs to be disseminated much longer because it concerns the system.

The quality of interaction in online learning through IGDF does not show significant increase, but from the aspect of variation experienced types of postings increase. In one pathway discussion forum discussion models (linear) all students post contains any response. In the post IGDF ranges include presentations, questions and responses.

Students' perceptions of the implementation of the learning IGDF Research in ELT include a) activity in IGDF $61.54 \%$ said good, b)

Enhancing Learning Interaction through Inter-Forum Group Discussion in 80 Online Learning: A Case Study on Online Teaching of Research in English Language Teaching Course 
interaction in group proved to be $50 \%$ stating that it was not communicated to the members in the group, c) $61.53 \%$ of students do not feel the ease in communicating f) material yet uploaded group discussions based on the discussion group are $65.38 \%$. There were $76.93 \%$ students stated that IGDF facilitated them to improve the understanding of the module material. Confidences of students to IGDF not show a positive response, there is evidence that disagrees 69.23.

\section{REFERENCES}

Bender, Tisha. 2003. Discussion-based online teaching to enhance student learning. Virginia:Stylus Publishing.

Clark. Ruth Colven \& Richard E. Mayer. 2002. e-learning and the science of instruction. San Francisco. Pfeiffer an Inprint of Wiley.

Loncke. F.T; Dudding.C.C; Kim.J (2009) The use of online discussion forums for ethics training. CONTEMPORARY ISSUES IN COMMUNICATION SCIENCE AND DISORDERS Volume 36 • 57-62 • Spring 2009 (C) NSSLHA. http://www.asha.org/uploadedFiles/asha/publications/cicsd/2009SThe UseofOnlineDiscussionForums.

Gunawardena and K.LaPointe.2003. Planning \& management in distance education. Edited By Santosh Panda : London and Sterling, VA

Hrastinski.Stefan. 2008. Asynchronous and synchronous e-learning. EDUCAUSE Quarterly, vol. 31, no. 4 (October-December 2008)

Mastering Online Discussion Board Facilitation Resource Guide Copyright 2009 http://www.edutopia.org/pdfs/stw/edutopia-onlinelearningmastering-online-discussion-board-facilitation

Mayes. Terry . 2006. Theoretical perspectives on interactivity in e-learning. Interactions in Online Education. Canada: Routledge 2 Park Square, Milton Park, Abingdon, Oxon OX14 4RN

Mishra. Sanjaya \& Juwah. Charles.2006. Interactions in online discussions a pedagogical perspective. Interactions in Online Education. Canada: Routledge 2 Park Square, Milton Park, Abingdon, Oxon OX14 4RN

Oren A, Mioduser D., and Nachmias.R. (2002) The Development of social climate in virtual learning discussion groups. The International review of Research in Open and Distance Learning. Volume 3 no.1. April 2002.

Peretz. Samuels.2014. Ghosts, stars, and learning online: analysis of interaction patterns in student online discussions. IRRODL Vol 15, No 3 (2014)

Raleigh D. (2000) Keys to Facilitating Successful Online Discussions. Vol. 7, No. 3: November 15, 2000 . Coordinator of technical training and instructional technology, media development center, University of Wisconsin-Eau Claire. http://www.uwsa.edu/ttt/raleigh.htm

Enhancing Learning Interaction through Inter-Forum Group Discussion in

Online Learning: A Case Study on Online Teaching of Research in English

Language Teaching Course 
Richards. Jack C \& Willy A. Renandya. 2002. Methodology in language teaching. United Kingdom. Cambridge University Press.

Simonson, M., Smaldino, S., Albright, M., \& Zvacek, S. (2012). Teaching and learning at a distance: foundations of distance education. 5th ed. Boston: Pearson.

Sunu Dwi Antoro. 2007. Pembaharuan dalam pembelajaran bahasa inggris. Modul 8. Jakarta. Universitas Terbuka

Teeler. Dede \& Peta Gray. 2000. How to use internet in ELT. Malaysia. Longman

Weller. Martin. 2002. Delivering learning on the net. London. Stylus Publishing Inc. 